https://artnodes.uoc.edu

\title{
Aprender de la caída, hacer con el desgarro: paradojas de la melancolía lúdica en "Gris"
}

\author{
Shaila García-Catalán \\ Universitat Jaume I \\ Aarón Rodríguez-Serrano \\ Universitat Jaume I \\ Marta Martín-Núñez \\ Universitat Jaume I
}

Fecha de presentación: octubre de 2020

Fecha de aceptación: noviembre de 2020

Fecha de publicación: enero de 2021

\section{Cita recomendada}

García Catalán, Shaila; Rodríguez Serrano, Aarón; Martín Núñez, Marta. 2021. «Aprender de la caída, hacer con el desgarro: paradojas de la melancolía lúdica en 'Gris'». En: L. Benítez; E. Berger (coord.) «Artes en tiempos de pandemia». Artnodes, núm.27: 1-10. U0C. [Consulta: dd/mm/aa]. http://doi.org/10.7238/a.v0i27.374909

\footnotetext{
SOCDERIGHISRESERVED

Los textos publicados en esta revista están sujetos -si no se indica lo contrario- a una licencia de Reconocimiento 4.0 Internacional de CreativeCommons. La licencia completa se puede consultar en https://creativecommons.org/licenses/by/4.0/deed.es_ES.
}

\section{Resumen}

Esta investigación parte de una concepción del videojuego como un «sistema afectivo» (Anable, 2018) que permite ensayar la relación con el mundo, y no evadirse de él, para analizar cómo se articula la melancolía lúdica. Aunque los discursos hegemónicos de nuestro tiempo inviten a la felicidad, el arte permite hacer algo con lo que falta: señala y nombra las sombras que nos habitan. Para ello, tomamos como caso de estudio Gris (Nomada Studio, 2018), que se propone como una alegoría de la melancolía, donde, a través de las herramientas de análisis textual y ludonarrativo, exploramos si se trata de una experiencia sustentada sobre el flow colorista que invita al descubrimiento relajado o si, por el contrario, realmente utiliza el lenguaje propio del videojuego para reflexionar sobre la complejidad de la experiencia melancólica. Como señala 


\title{
artnodes
}

https://artnodes.uoc.edu

Aprender de la caída, hacer con el desgarro: paradojas de la melancolía lúdica en «Gris»

Farca (2018), los videojuegos distópicos están levantados sobre un núcleo profundamente utópico y esperanzador. Los resultados señalan cómo no podemos clasificarla únicamente como una experiencia flow colorista que invita al descubrimiento relajado, pues la experiencia no puede ser considerada únicamente desde su vertiente artística, ya que exige que se ejecuten mecánicas de reconfiguración, recolección y caza; por ello, empuja a una resolución en la que el jugador exige clausura, algo que contradice el sentir melancólico.

\section{Palabras clave}

melancolía, tiempo, videojuego, Gris, ludonarrativa.

\section{To learn from the fall, to deal with anguish: paradoxes of playful melancholy in «Gris»}

\begin{abstract}
This paper departs from a conception of video games as an "affective system" (Anable, 2018) that allows us to test our relationship with the world, not to escape from it, in order to analyse how melancholy is articulated in games. Although the hegemonic discourses of our time invite to happiness, art allows us to make something with what is missing: it points out and names the shadows that inhabit us. To do so, we analyse Gris (Nomada Studio, 2018) as a case study, which is proposed as an allegory of melancholy, using the tools of textual and ludonarrative analysis, to explore whether it is an experience based on the colourful flow that invites to a relaxed discovery or if it really uses the language of video game to reflect the complexity of the melancholic experience. Although we can play melancholy, sadness and dystopia, as Farca (2018) warns, dystopian video games are centred on a deeply utopian and hopeful core. The results point out we cannot classify it solely as a colourful flow experience that invites relaxed discovery, as the video game cannot be considered solely from its artistic side, as it requires the execution of mechanics of reconfiguration, gathering and hunting; thus, the video game, by its own nature, pushes for resolution while the player demands closure, something that contradicts the melancholic feeling.
\end{abstract}

\section{Keywords}

melancholy, video game, Gris, Iudonarrative, time

\section{El jugador busca perder para recuperar sentido. Lo clásico y lo postclásico}

Aprender a perder es, posiblemente, uno de los aprendizajes más dolorosos, pero, a la vez, más humanizantes. Es lógico que los debates académicos de los videojuegos se hayan organizado en torno a la basculación de la potencia entre el jugador y el juego. En sus rudimentos más básicos, la lógica subjetiva del juego, antes de suponer un estudio de los límites simbólicos del mundo, permite la aprehensión de una ilusión imaginaria de control y un ensayo de la pérdida. El estudio de Freud sobre los primeros gestos lúdicos infantiles -el de tirar, perder y recuperar un carretel para tratar la ausencia de los padres- muestra las tentativas del niño de saber hacer con la ausencia de sus objetos, incluso con su presencia. Precisamente los primeros gestos del juego del niño le permitieron descubrir a Freud Io infatigable de las exigencias pulsionales: el sujeto no se detiene en la satisfacción -el juego no se queda con la alegría de recuperar el carretel, como el apostador tampoco detiene su próxima apuesta cuando gana-, pues las pulsiones corporales siempre exigen más, sugiriendo el desbordamiento del sujeto, traicionando sus contenciones e intenciones conscientes. Esto también explica el goce lúdico, que es otro nombre del más allá del principio de placer (Freud, 2013b) y que nos muestra que el jugador goza al perder, pues la falta es el motor del juego (y del deseo), porque reclama buscar y recuperar un objeto imposible que, en tanto está para siempre perdido, es inconsciente. El deseo de jugar no se organiza, por tanto, por lo que uno puede ganar, sino por lo que uno no sabe que perdió y que no hay modo alguno de colmar. Podríamos decir que se construye en torno a un «arte del fracaso» (Juul, 2013).

Por todo ello, los videojuegos, como las grandes narraciones, voltean alrededor de una pérdida y un vacío estructural que agujerea el saber y pone un límite en el hacer.

«Toda narración supone una alternativa entre Deseo y Ley, pérdida y recuperación. Algo debe perderse para ser, posteriormente, recuperado mediante su economía libidinal. La lógica de los posibles narrativos pasa por la elección de un camino que debe ser transitado por el personaje y el mundo que lo rodea. Inscribir una mirada en el tiempo a través de la vivencia de éste es el objetivo esencial del cine clásico» (Company, 2014: 81). 


\section{artnodes}

https://artnodes.uoc.edu

Aprender de la caída, hacer con el desgarro: paradojas de la melancolía lúdica en «Gris»

Patel y Fernández-Vara (2015) cuestionan una rápida adscripción de los videojuegos como medio posmoderno, porque no hay nada inherente en ellos que garantice realmente la dinámica de poder ascendente que Lyotard (2019) propone en las narrativas emergentes. Esto es algo que confirma el concepto «libertad dirigida» en el videojuego (Navarro-Remesal, 2016) al marcar los límites y la potencia del jugador a pesar de la ilusión de control que le otorga el juego. Consideramos que esta vez puede sernos útil no pensar los videojuegos desde el poder, sino desde la relación que el discurso lúdico propone con la falta.

Podríamos convenir en que los discursos postclásicos hacen gala de la desorganización estructural, de la complejidad y de la fuga de sentido. La enunciación amenaza con enmarañar al sujeto de la comprensión y maniatar al sujeto de la acción. Sin embargo, no podemos olvidar que la mismísima «fuga de sentido es una propiedad de estructura del sentido» (Miller, 2003: 19), que es metonímico y siempre parece esperar un tiempo después o en otro lado. Ningún desencanto de una época supera la creencia en el sentido común que acune nuestro principio de realidad. Y es que si algo enseña el recorrido por la historia cultural de la melancolía es que lo que atraviesa las épocas de forma más o menos velada es una lamentación por la condición humana, no tanto por la futilidad de su destino y de su existencia, sino por la falta de causalidad, incluso en las épocas de mayor creencia religiosa.

\section{Evolución histórica y planteamiento postclásico de la melancolía en los videojuegos}

Partimos de una concepción del videojuego no tanto como sistema de representación que «funciona como una huida de la agonía de la vida diaria donde las apuestas son reales e inciertas» (Wark, 2008), sino como un «sistema afectivo» (Anable, 2018) que permite ensayar la relación con el mundo, no evadirse de él. Se juega la melancolía, la tristeza, la distopía, pero, como advierte Farca (2018), Ios videojuegos distópicos están centrados en un núcleo profundamente utópico y esperanzador. Algunos títulos publicados en los últimos años exploran estas cuestiones, como Flower(ThatGameCompany, 2009), Firewatch (Campo Santo, 2016) o What Remains of Edith Finch (Giant Sparrow, 2017). En este texto nos proponemos el análisis de Gris (Nomada Studio, 2018) como caso de estudio, un videojuego que asienta su ludonarrativa sobre la melancolía para preguntarnos en qué medida esto supone un gesto postclásico.

Precisamente, al tiempo que aparecen videojuegos que juegan la distopía o el malestar, aparecen también otros que proponen una suerte de flow, término que plantea Csikszentmihalyi (2010) -no precisamente desde la academia del videojuego, sino desde la psicología de la felicidad- con la hipótesis de que toda actividad de la experiencia que se propone como una actividad de flujo ofrece sensación de descubrimiento, un sentimiento creativo de absorción que da una nueva realidad. Es necesario señalar que en los últimos años -y muy especialmente en la esfera del videojuego (NavarroRemesal, 2020: 132-141)-, dicho concepto ya ha sido puesto en crisis, desvelando su complicidad con ciertos usos de programación biopolítica propios del modelo neoliberal.

Queremos saber si Gris, que se propone como una alegoría de la melancolía, es en realidad una experiencia sustentada sobre el flow colorista que invita al descubrimiento relajado o si, por el contrario, realmente utiliza el lenguaje propio del videojuego para reflexionar sobre la errancia del ser y la complejidad de la experiencia melancólica.

Zunzunegui plantea que «hay una melancolía propiamente cinematográfica que se expresa en el intento de superar la censura entre imágenes para reunir en el mismo cuadro a los personajes de la historia» (2017: 79). Es decir, el lenguaje cinematográfico se ha construido desde la fragmentación, la separación de los cuerpos que solo se reúnen gracias la continuidad del raccord y a la sutura entre los planos. Está todavía por pensar cuál sería la melancolía propiamente ludográfica, especialmente si tenemos en cuenta que, entre las muchas posibilidades del medio, a menudo se utilizan como mecánicas privilegiadas el deslizamiento, el desplazamiento, el deambular, buscando una suerte de simulación propia del ensimismamiento melancólico -véanse Proteus (Ed Key y David Kanaga, 2013) o Journey (Dualshock, 2012)-. Para comenzar dicha tarea, parece sensato repensar la evolución de la melancolía como afecto.

Ciertamente, el carácter esquivo de la evolución histórica de la melancolía ha sido ya topografiado en multitud de trabajos previos (véanse Gurméndez, 1994; o Pujante, 2018). Pensada como afección de los cuerpos, valientemente tomada en ocasiones como condición básica del pensamiento (Kristeva, 2017), la melancolía apunta a una manera de estar en el mundo en la que se provoca un desgarro, una incompatibilidad entre los marcos exteriores del sujeto y su propia disposición afectiva interior. La melancolía es la manera en la que el cuerpo ha generado una fricción frente a los marcos simbólicos normativos y aceptados de cada época: frente a las normas de la ciudad, las leyes y los dioses en la antigüedad, en el medievo -con su acedia o disgusto ante la vida-, en los vanitas barrocos e incluso en las recuperaciones de los elementos míticos que se opusieron frontalmente al proyecto de las luces en el XIX. En oposición a la tranquilizadora aceptación del logos, los cuerpos se han valido de la melancolía para dejar constancia de su imposible domesticación, de su desencaje.

En el siglo xx, no obstante, la angustia y la melancolía como significantes fueron sustituyéndose por la ansiedad y depresión. Estos, por la medicalización de la vida cotidiana, se abren ya no como síntomas a los que interrogar, sino como patologías a erradicar. El yo contemporáneo se piensa a modo de yo neuroquímico o neurobiológico por la irrupción de las neurociencias y el cognitivismo. En esta idea, el videojuego ha plantado sus raíces, siendo a la vez síntoma y texto 


\section{artnodes}

https://artnodes.uoc.edu

Aprender de la caída, hacer con el desgarro: paradojas de la melancolía lúdica en «Gris»

privilegiado de esa constante búsqueda neoliberal por la felicidad (Oliva, Pérez-Latorre y Besalú, 2018). Como intentaremos demostrar en las siguientes páginas, Gris cumplirá ambas coordenadas.

\section{Análisis ludonarrativo y textual de Gris: elementos lúdicos, temáticos y plásticos}

Gris plantea en su secuencia inicial, previa a los créditos de inicio del juego, una experiencia de pérdida. La protagonista del juego, literalmente en manos del Otro, experimenta la pérdida de la voz propia, que se traduce en la fractura del mundo que la sostiene y sus colores. El avatar queda sin voz, mientras su mundo se desmorona (fig. 1). La pérdida se inscribe así desde el arte del juego -banda sonora y color- para activar los procesos ludonarrativos a partir de su recuperación.

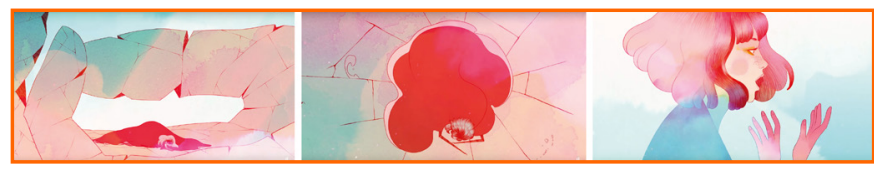

Fig. 1. Secuencia inicial de Gris.

Estamos en el territorio de la bilis negra, idea que sigue resonando en artistas contemporáneas, como Susan Gofstein (fig. 2). El nombre del videojuego ya apunta hacia esa gama indeterminada entre la luz y la oscuridad que sitúa al jugador ante la pérdida, pues la melancolía hace palidecer los colores del mundo.
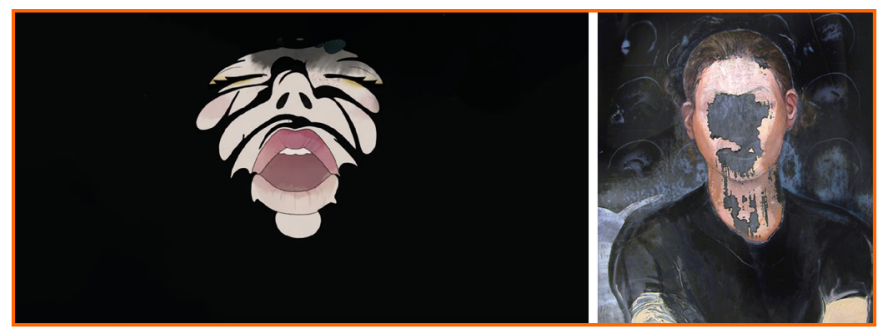

Fig. 2. Gris; Resonance (Susan Gofstein, 2014)

La importancia del color como elemento ludonarrativo está justificada por el diseño artístico del juego, basado en las acuarelas del ilustrador Conrad Roset. Se trata del rasgo fundamental y diferenciador del videojuego. Roset evoca las lágrimas y una angustia indecible. La acuarela llora lo que no se puede decir desplegando una melancolía naíf que alude al antiacademicismo, la espontaneidad y la ingenuidad. El clímax del juego llega cuando una lágrima brota de la estatua de piedra recompuesta, después de haber ido recuperando los colores y la voz a lo largo de los espacios transitados.

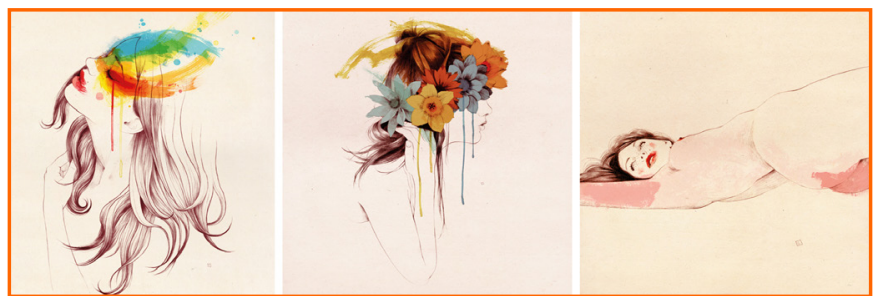

Fig. 3. Musas de Conrad Roset

Es en este universo estético en el que emerge una reflexión sobre las propias mecánicas videolúdicas y, en primer lugar, sobre la caída. "Lo enmudecedor para el espectador es que sabe que la caída es puro lanzamiento, una última elección: morir o morir, pero con una decisión subjetiva, esto es, morir como sujeto» (GarcíaCatalán, 2018: 119). La caída implica también la pérdida del horizonte fijo y la «retirada de un paradigma estable de orientación que ha establecido a lo largo de la modernidad los conceptos de sujeto y objeto, de tiempo y de espacio» (Steyerl, 2014: 17). Quizás, como apunta Català, «pensar al borde del abismo es tan peligroso y difícil -no hay dónde agarrarse- que quizá vale la pena dejarse caer y empezar a pensar en el abismo, durante la propia caída: haciendo de la caída un discurso» (2016: 103). Los títulos de crédito de Gris se sitúan en esta caída (fig. 4). Una caída física, resignada, tranquila, consciente, y simbólica: el sujeto se hace cada vez más pequeño y los colores se van desaturando hasta acabar en el blanco, en una rima visual con una última caída final, que nos llevará a la resolución del juego.

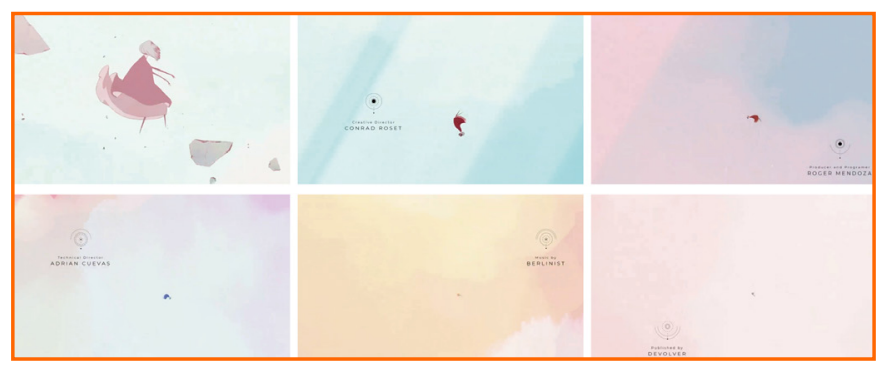

Fig. 4. Inicio de Gris: caída.

Sin embargo, como avanzábamos, en el videojuego hay una obligación a la acción: el avatar no puede retirarse del mundo, sino quedar, aun en su caída, en un avanzar obligado. En el momento en el que el jugador toma el control del avatar por primera vez, tras la larga caída, lo único que el juego permitirá como mecánica será andar y caer al suelo. La caída pasa de estar escrita en la narrativa estructurada a convertirse en una posibilidad de acción y relación con el mundo, siendo la única posible durante los primeros compases.

Esta situación no se alarga mucho -el videojuego requiere acción- y, de forma un tanto arbitraria, el avatar ganará otras 


\section{artnodes}

https://artnodes.uoc.edu

Aprender de la caída, hacer con el desgarro: paradojas de la melancolía lúdica en «Gris»

posibilidades mecánicas, como el salto. Esto contradice profundamente el sentir melancólico, pero recordemos la clave más importante del avatar del videojuego: es un ser obligado a hacer. Así, el avatar irá progresando en mecánicas y en posibilidades de acción, todas ellas vinculadas a la maleabilidad del vestuario y la interacción con el entorno. El vestido otorga agencia, como la túnica en Journey: puede convertirse en una piedra cuadrada para destruir los monumentos del escenario, resistir al viento 0 desestabilizar plataformas. Permite impulsarnos en el aire entre aleteos de mariposas, bucear o congelarnos. Y, al mismo tiempo, el vestido remite al universo naíf y fantástico de la ilustración infantil de Rébecca Dautremer (fig. 5).
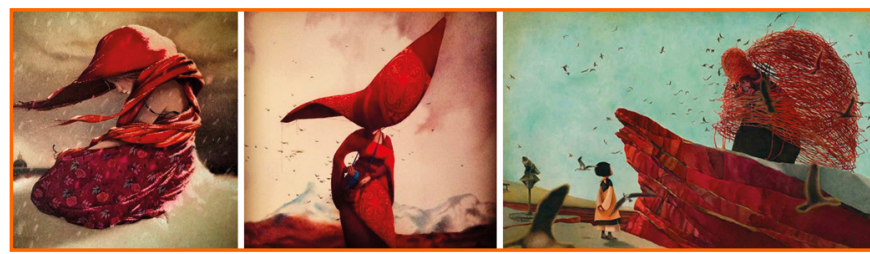

Fig. 5. Rébecca Dautremer.
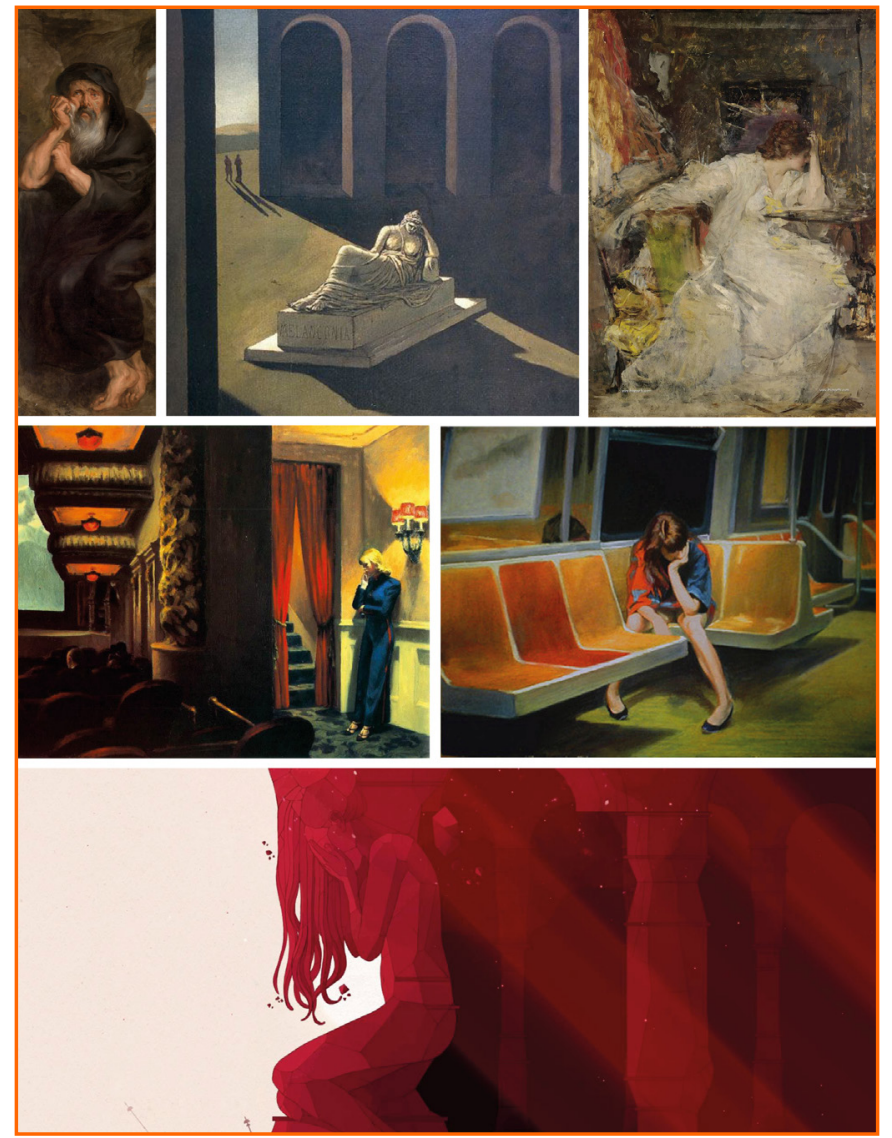

Fig. 6. Heráclito, el filósofo que Ilora (Anónimo, taller Rubens, 1636); Soledad (melancolía) (Giorgio de Chirico, 1912); Título desconocido (Vicente Palmaroli), Cine en New York (Ed-ward Hopper, 1939); Q Train (Nigel Van Wieck, 2017) y Gris.
La agencia lúdica imposibilita la postración melancólica, que se traslada a la capa artística. Así, tras el derrumbe inicial, en Gris toma presencia el gesto canónico de la melancolía, esto es, el sujeto cabizbajo, apoyado en su mano con una pose debilitada. Un motivo del que la historia del arte nos ha dejado incontables muestras y que en el juego toma cuerpo a partir del leitmotiv de las esculturas que pueblan el mundo (fig. 6).

La estética de la caída es fundamental en Gris; más allá de los créditos iniciales, el avatar volverá a descender hasta las profundidades del gameworld, pero estas caídas que nos trasladan de mundos ya no serán al vacío: son descensos 0 ascensos que nos hacen avanzar.

Este avance no es siempre hacia adelante, como marca la tradición de los juegos de plataformas y la fluidez del scroll. El recorrido nos llevará hacia la derecha, pero también hacia la izquierda y, sobre todo, hacia abajo y, ocasionalmente, hacia arriba. El avance se torna así en un deambular, una errancia marcada por una suerte de desorientación animada por la invitación al descubrimiento. En un momento del juego, el mundo se desdobla y se invierte, y la exploración ocurrirá boca abajo, obligando al jugador a readaptar todas las mecánicas espaciales.

Como hemos apuntado al principio de este texto, con el término acedia, el medievo ya captó la relación entre la tristeza y el deseo. La acedia inmoviliza, inhabilita para el trabajo. Suspende el hacer porque el sujeto queda a expensas de un goce de abandono: podría decirse que el sujeto melancólico se identifica con la ruina, con lo insalvable. Ahora bien, ¿qué lugar le queda al sujeto melancólico en el videojuego cuando su condición es que precisamente queda afectado por una desvitalización en tanto falta el motor del deseo? ¿Qué esperar del jugador obligado a mover un avatar afligido y hastiado de la pereza o de la apatía?

Precisamente Sontag (2011) apunta que el estilo del melancólico es la inmersión, la concentración total; así, vemos cómo lo interesante del discurso lúdico de la melancolía es que el gameworld contribuye a su ensimismamiento. El sentir melancólico se traslada al diseño del mundo y el errático recorrido se hará entre desiertos,

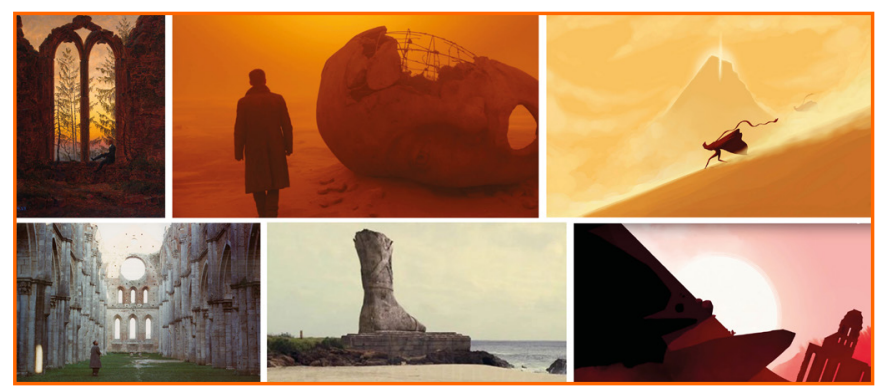

Fig. 7. Ruinas del monasterio de Oybin (el soñador) (Caspar David Friedrich, 1835), Blade Runner 2049 (Denis Villeneuve, 2017), Journey; Nostalgia (Andrei Tarkowski, 1983); Perdidos (episodio 5x16, J.J. Abrams, 2009) y Gris. 


\section{artnodes}

https://artnodes.uoc.edu

Aprender de la caída, hacer con el desgarro: paradojas de la melancolía lúdica en «Gris»

bosques y profundidades marinas en ruinas, donde el viento, la lluvia 0 la arena adquieren roles antagónicos. Caemos en un mundo de arquitecturas derruidas. La ruina siempre está cerca en cualquier imagen alegórica sobre la melancolía. Como apunta Zunzunegui, «podemos postular que las ruinas forman parte del eje de los subcontrarios del eje semántico que forman naturaleza y cultura» (2017: 116), ya que, como indica Eco «la ruina es apreciada precisamente por su carácter incompleto, por las marcas que el tiempo ha dejado en ella» (2015: 285).

El espacio del juego se articula como un universo continuo en el que todo está conectado, todo fluye. Se renuncia así a la articulación de un punto de vista fragmentado legado del lenguaje cinematográfico hegemónico. Sin embargo, la enunciación, lejos de ofrecer una mirada neutra (Martín Núñez, 2020), gestiona a través del punto de vista las escalas, enfatizando especialmente la pequeñez del avatar frente al mundo, en el que a veces solo se distingue una pequeña silueta que deambula y de la que solo se escuchan sus pasos (fig. 8). Esta pequeñez, propia de la estética de lo sublime, contrasta con algunos de los motivos visuales que emergen de entre las ruinas. Este es el caso de la piedra que se impone, recordando la geometría, pero también la gravedad, de esa roca de 10 real que no deja de caer en la historia de nuestras imágenes (fig. 9) como testigo de lo impensable de nuestra civilización.

El videojuego, además, recoge la experiencia narratológica escrita sobre lo que Genette llamó el pseudo-tiempo para hablar del tiempo ficcional que se refiere al tiempo real/verdadero -true- necesario para
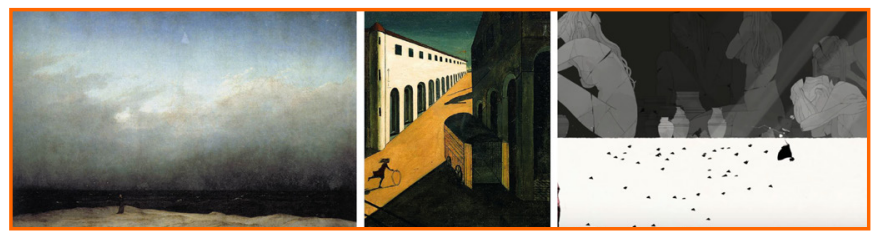

Fig. 8. Monje a la orilla del mar (Caspar David Friedrich. 1808-1810); Misterio y melancolía de una calle (1914, De Chirico); Gris.

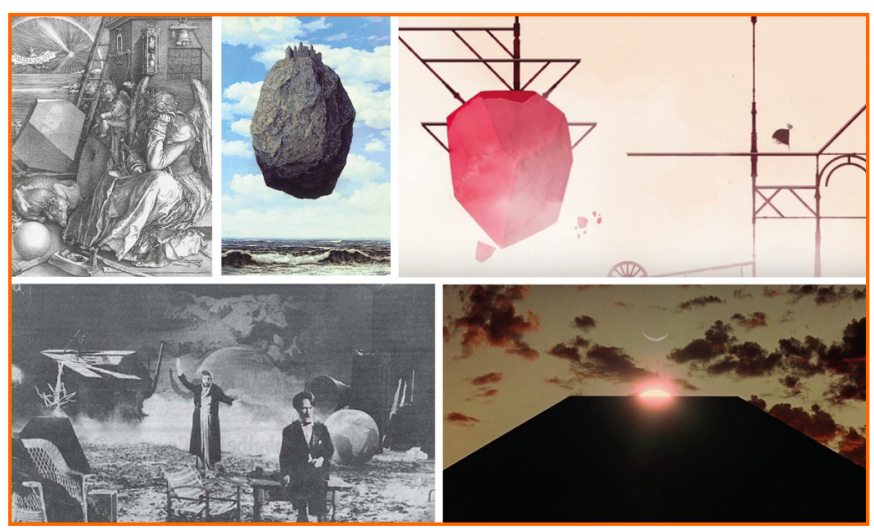

Fig. 9. Monje a la orilla del mar (Caspar David Friedrich. 1808-1810); Misterio y melancolía de una calle (1914, De Chirico); Gris. cruzar o atravesar el espacio -un libro, que también se puede aplicar a un videojuego- (1980: 34). La temporalidad interna del gameworld queda así suspendida, supeditada solo al deambular del avatar, que puede extenderse durante horas. En su vagar, el melancólico querría precipitarse a la muerte, pero en Gris no es posible (ni la ficcional ni la funcional). Precisamente es la caída la que fuerza el bucle de la repetición intrínseca al videojuego.

Sin embargo, el propio diseño del mundo sí nos remite a través de las mecánicas y los motivos visuales a cierta temporalidad. El jugador tendrá que resolver puzles temporales para continuar su recorrido, mientras que los engranajes de un reloj se repiten en distintas arquitecturas del juego. No es casualidad que se nombre a la melancolía como temperamento saturnino, porque se asoció a Cronos (fig. 10).

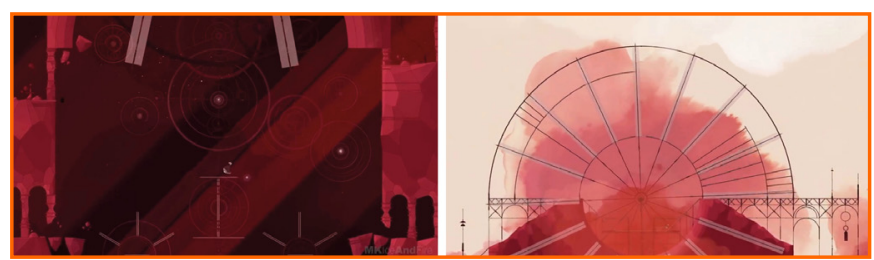

Fig. 10. Motivos visuales vinculados a la medición del tiempo en Gris.

El origen astronómico de la melancolía está presente también en Gris (fig. 11), tanto en el diseño artístico como a nivel mecánico. Para avanzar, el jugador debe buscar y recoger en el mundo pequeños astros que después le permitirán crear constelaciones. Esta mecánica es la que, precisamente, contradice toda la filosofía melancólica: la exploración ya no es tan errática, como se propone en un principio; en realidad, está motivada por la consecución de las esferas de luz que marcan el sentido.

Esta idea nos lleva directamente al problema de la alteridad. Como ya sabemos, Freud marcó una importante distinción entre duelo y melancolía. Mientras el duelo implica el tratamiento subjetivo, el

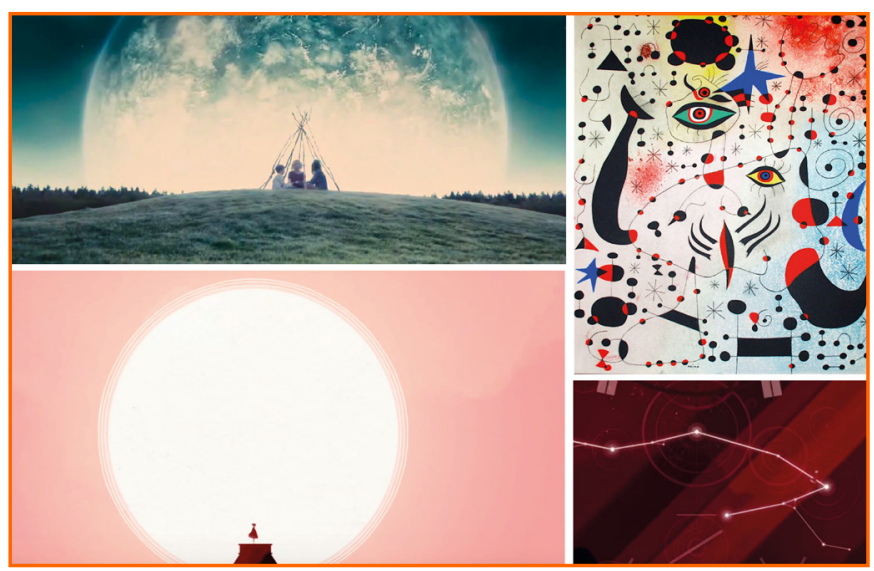

Fig. 11. Melancolía (Lars von Trier, 2011); Constelaciones (Joan Miró, 1941); Gris. 


\section{artnodes}

https://artnodes.uoc.edu

atravesamiento de una pérdida de objeto (un enamorado, la muerte de un ser querido, etc.), en la melancolía esa relación con el objeto se complica por un conflicto de ambivalencia (amor y odio por el objeto perdido) que se vuelve contra el yo. Si en el duelo permite al sujeto declarar lo perdido como muerto, lo que permite renunciar y proseguir viviendo, en la melancolía los afectos sobre el objeto perdido recaen sobre el sujeto, por lo que el sujeto se menosprecia con gran intensidad, se victimiza. La sombra del objeto perdido recae sobre el sujeto (Freud, 2013a: 254-255). Por ello, hablaba del melancólico como un caníbal que engulle el objeto amoroso perdido, lo convierte en parte de sí mismo.

La furia, que en la melancolía retorna sobre el yo, en Gris toma la posición de antagonistas en forma de un animal alado y de un monstruo marino, motivos icónicos en la historia del arte (fig. 12). La imposibilidad de la muerte en el juego hace que estos enemigos nunca consigan matar, solo dificultar el avance y, al mismo tiempo, empujar a él. La furia que ejercen se transforma, así, de algo externo al propio jugador y sus habilidades. Esta tesis queda demostrada cuando los antagonistas se transforman en una versión monstruosa del avatar que lo engulle y que supone el último reto antes de la resolución del juego (fig. 13). Consideramos, por tanto, que el videojuego contemporáneo dispone un sujeto melancólico que debe lidiar con la furia que él desata, con su propia aversión.

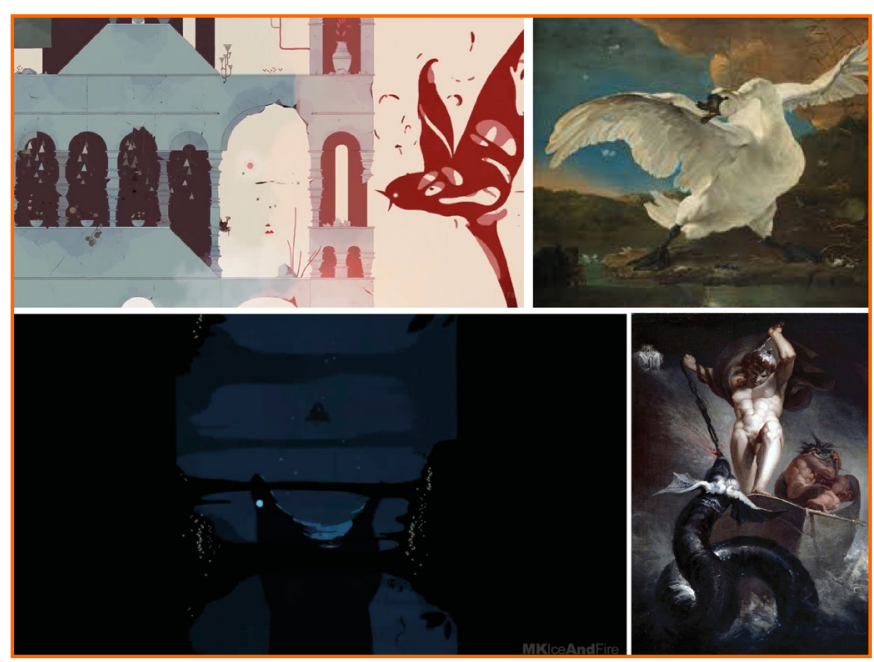

Fig. 12. La furia de la golondrina en Gris; El cisne amenazado (Jan Asselijn, 1650). E monstruo marino en Gris y Thor peleando contra la serpiente Jörmundgander (Johann Heinrich Füssli, 1788).
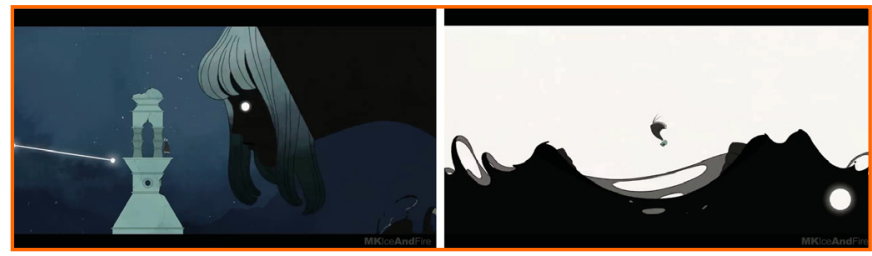

Fig. 13. El avatar y su versión monstruosa en Gris.

\section{Conclusiones}

Como anota Hermsern, aunque «desde que el mundo es mundo, el ser humano ha tenido que hacer frente a pérdidas, decepciones y contratiempos, [...] da la impresión de que en la actualidad estamos peor preparados que nunca para ello» (2019: 19). Ahora bien, allí donde desaparecen rituales para registrar simbólicamente la pérdida, aparecen los discursos artísticos para tematizarla y para saber hacer algo con ella. Podríamos decir que, aunque la felicidad sea un imperativo en nuestro tiempo, el arte sigue ofreciendo un lugar para abordar nuestra falta. La melancolía en el arte aún señala y nombra las sombras que nos habitan. Es urgente pensar la melancolía hoy, pues cuando amenaza con faltar un lugar simbólico que permita alojar la falta, amenaza también la desazón, la caída literal o incluso el odio de sí. Como apunta Hermsen, «Sea como fuere, habrá que crear de nuevo espacios para la decepción, el miedo y la tristeza en nuestra sociedad fuertemente medicalizada y comercializada, para aprender a encarar nuestras pérdidas» (2019: 39).

Gris plantea una experiencia ludonarrativa y estética que reivindica la melancolía en un contexto visual que hereda la tradición estética de la melancolía pero también arrastra cierta ingenuidad y banalidad del pensamiento positivo. Pero no podemos clasificarla únicamente como una experiencia flow colorista que invita al descubrimiento relajado, pues la experiencia no puede ser considerada únicamente desde su vertiente artística, ya que exige que se ejecuten mecánicas de reconfiguración, recolección y caza. Por eso mismo, la propia naturaleza videolúdica nos plantea una paradoja. La experiencia de la melancolía demanda caída, errancia, deambular y furia; y el videojuego como medio demanda justo lo contrario al jugador -véanse, al respecto los trabajos de Nelson Zagalo (2007)-.

Gris, por tanto, nos permite preguntarnos si la melancolía en el videojuego es una excusa temática que toma cuerpo principalmente en los significantes artísticos, pero donde no puede existir en una lógica ludonarrativa. Frente a la caída, la errancia y la furia, el videojuego exige acción, dirección y resolución, cualidades que se distancian profundamente del sentir melancólico. Gris incorpora estos elementos ludonarrativos haciendo de la caída una mecánica significante; de la exploración, una búsqueda errática; y de los enemigos, una furia contra uno mismo -y sus habilidades-; pero, al final, no dejan de contradecir el hastío y la apatía propia de lo melancólico. El videojuego empuja a una resolución y el jugador, que nunca ha abandonado la lógica del relato clásico, exige una clausura en la que se restaure el agujero de sentido abierto en el inicio, en el que se suture la herida de la experiencia de pérdida. Por tanto, la experiencia de juego convierte lo que se disponía como pura melancolía errante y sin rumbo en una travesía con destino: pasado el juego, ¿elaborado el duelo?. 


\section{artnodes}

\section{Financiación}

El presente trabajo ha sido realizado en el marco de los proyectos de investigación El diseño narratológico en videojuegos: una propuesta de estructuras, estilos y elementos de creación narrativa de influencia postclásica (DiNaVi) (código 18I369.01/1), dirigido por la Dra. Marta Martín-Núñez y Análisis de identidades discursivas en la era de la posverdad. Generación de contenidos audiovisuales para una educomunicación crítica (AIDEP) (código 18I390.01/1) dirigido por el Dr. Javier Marzal-Felici. Ambos fueron financiados por la Universitat Jaume I, a través de la convocatoria competitiva de proyectos de investigación de la UJI para el período 2019-2021.

\section{Uso de imágenes}

Las imágenes utilizadas como figuras en este artículo son elementos centrales del análisis, realizado únicamente con fines científicos en el ámbito académico.

\section{Referencias bibliográficas}

Anable, Aubrey. 2018. Playing with Feelings: Video Games and Affect. Minneapolis: University of Minnesota Press. DOI: https://doi. org/10.5749/j.ctt20mvgwg

Català, Josep. M. 2016. La gran espiral. Capitalismo y paranoia. Vitoria-Gasteiz: Sans Soleil Ediciones.

Company, Juan Miguel. 2014. Hollywood. El espejo pintado (19012011). Valencia: Publicacions de la Universitat de València.

Csikszentmihalyi, Mihály 2010. Fluir (Flow): Una psicología de la felicidad. Barcelona: Kairós.

Eco, Umberto. 2015. Historia de la Belleza. Madrid: Debolsillo.

Farca, Gerald. 2018. Playing Dystopia: Nightmarish Worlds in Video Games and the Player's Aesthetic Response. Wetzlar: Transcript. DOI: https://doi.org/10.14361/9783839445976

Freud, Sigmund. 2013a. «Duelo y melancolía (1917 [1915])». Obras completas. Tomo XIV. Buenos Aires: Amorrortu.

Freud, Sigmund. 2013b. «Más allá del principio de placer (1920)». Obras completas. Tomo XVIII. Buenos Aires: Amorrortu.

García-Catalán, Shaila. 2016. «Los desheredados. El Otro pulverizado en nuestra cultura visual». En Javier Marzal et. al. (eds.). Crisis de lo real. Representaciones de la crisis financiera de 2008 en el audiovisual contemporáneo. Valencia: Tirant Humanidades.

Genette, Gerard. 1980. Narrative Discourse. An Essay in Method. Ithaca, New York: Cornell University Press.

Gurméndez, Carlos. 1994. La melancolía. Madrid: Espasa-Calpe.
Hermsen, Joke J. 2019. La melancolía en tiempos de incertidumbre. Madrid: Siruela.

Juul, Jesper. 2013. The art of failure: an essay on the pain of playing video games. Cambridge: MIT Press.

Kristeva, Julia. 2017. Sol negro: Depresión y melancolía. Barcelona: Wunderkammer.

López, Rosa. 2016. «Tristeza, ¿enfermedad o cobardía moral?» 0505-2016. Nucep. Sección clínica, mayo 5, 2016. Madrid: Instituto del Campo Freudiano. https://nucep.com/publicaciones/tristezaenfermedad-cobardia-moral/.

Lyotard, Jean-Françoise. 2019. La condición postmoderna. Madrid: Cátedra.

Martín-Núñez, Marta. 2020. «Encuadres. Diseñar la escritura audiovisual del videojuego». En Víctor Navarro (ed.). Pensar el juego. Valencia: Shangrila.

Miller, Jacques-Alain. 2003. Lo real y el sentido. Buenos Aires: Paidós.

Navarro-Remesal, Víctor. 2016. Libertad dirigida. Una gramática del análisis y diseño de videojuegos. Santander: Shangrila.

Navarro-Remesal, Víctor. 2019. «Ser todo, ser nada: la subjetividad del videojuego más allá del avatar». Tropelías. Revista de Teoría de la Literatura y Literatura Comparada, 31: 156-173. D0I: https:// doi.org/10.26754/ojs_tropelias/tropelias.2019313178

Navarro-Remesal, Víctor. 2020. «Meditaciones: Modos Zen, Contemplación y Lentitud en el Videojuego». En Víctor Navarro (ed.). Pensar el juego. Valencia: Shangrila.

Oliva, Mercè, Óliver Pérez-Latorre, y Reinald Besalú. 2018. «Choose, collect, manage, win! Neoliberalism, enterprising culture and risk society in video game covers». Convergence, 24(6):. 607-622. DOI: https://doi.org/10.1177/1354856516680324

Patel, Ansh, Fernández-Vara, Clara. 2015. «Postmodernism in Videogame Narratives». Game Studies II. http://lightnarcissus.com/ wp-content/uploads/2015/06/Postmodernism-in-VideogameNarratives.pdf

Pujante, David. 2018. Oráculo de tristezas. La melancolía en su historia cultural. Barcelona: Xoroi Ediciones.

Sontag, Susan. 2011. Bajo el signo de Saturno. Madrid: Penguin Random House.

Steyerl, Hito. 2014. Los condenados de la pantalla. Buenos Aires: Caja Negra Editora.

Zagalo, Nelson. 2017. «Narrative Design of Sadness in Heavy Rain». Journal of Science and Technology of the Arts, 9(2): 47-59. DOI: https://doi.org/10.7559/citarj.v9i2.246

Zunzunegui, Santos. 2017. Bajo el signo de la melancolía. Cine desencanto y aflicción. Madrid: Cátedra.

Wark, McKenzie. 2007. «Alegorías digitales (sobre Los Sims)». Artnodes, 7. 


\section{artnodes}

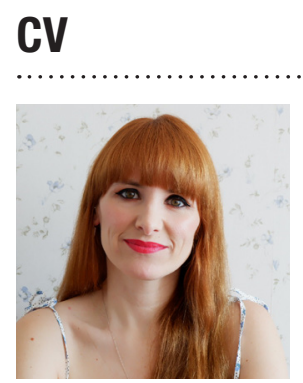

\section{Shaila García-Catalán}

Universitat Jaume I

scatalan@uji.es

Es profesora e investigadora en la Universitat Jaume I, donde trabaja el análisis crítico de los discursos y su relación con las subjetividades contemporáneas. Autora del libro La luz lo ha revelado. 50 películas siniestras (Ed. UOC, 2019), también ha escrito publicaciones nacionales e internacionales sobre fotografía, cine, series y videojuegos desde el análisis textual y el psicoanálisis. Participa en el proyecto El diseño narratológico en videojuegos. Una propuesta de estructuras, estilos y elementos de creación narrativa de influencia postclásica (DiNaVi), dirigido por la Dra. Marta Martín Núñez. Coordina el espacio de pensamiento Sala Caligari e imparte las asignaturas Cultura Visual y Medios de Masas, Narrativa Audiovisual y Modelos de Representación Cinematográfica.

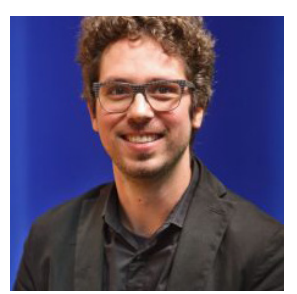

\section{Aarón Rodríguez-Serrano}

Universitat Jaume I

serranoa@uji.es

Es profesor e investigador en la Universitat Jaume I, donde trabaja sobre los tránsitos y las relaciones entre la filosofía del siglo xx (especialmente desde una perspectiva fenomenológica) y las metodologías de análisis fílmico, así como sus repercusiones en el panorama audiovisual contemporáneo. Ha trabajado especialmente las relaciones que se establecen entre representación audiovisual y Holocausto desde diferentes perspectivas: estudio de los textos audiovisuales nazis, procesos de posmemoria en el cine contemporáneo o en los videojuegos, dilemas éticos en torno a la representación de los genocidios, etc. Ha impartido las asignaturas Cultura Visual y Medios de Masas, y Narrativa Hipermedia y Análisis de Videojuegos en el grado en Diseño y Desarrollo de Videojuegos, entre otras. 


\section{artnodes}

https://artnodes.uoc.edu

Aprender de la caída, hacer con el desgarro: paradojas de la melancolía lúdica en «Gris»

\section{CV}

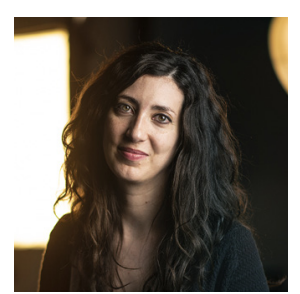

Marta Martín-Núñez

Universitat Jaume I

mnunez@uji.es

Es profesora e investigadora en la Universitat Jaume I, donde ha desarrollado una trayectoria académica vinculada al análisis de los discursos audiovisuales contemporáneos en el contexto de la complejidad narrativa posclásica y el entorno digital. Tiene un perfil multidisciplinar desde el que aborda diferentes objetos de estudio, especialmente alrededor de las nuevas narrativas y narrativas interactivas y los discursos fotográficos contemporáneos. Dirige el proyecto I+D El diseño narratológico en videojuegos: una propuesta de estructuras, estilos y elementos de creación narrativa de influencia postclásica (DiNaVi), financiado por la Universitat Jaume I, a través de la convocatoria competitiva de proyectos de investigación de la UJI para el período 2019-2021. Es miembro del Managing Committee de la acción europea COST Interactive Narrative Design for Complexity Representations. Imparte la asignatura Narrativa Hipermedia y Análisis de Videojuegos en el grado en Diseño y Desarrollo de Videojuegos, entre otras.

Universitat

Oberta

de Catalunya 